Revista Destaques Acadêmicos, Lajeado, v. 10, n. 3, 2018. ISSN 2176-3070

DOI: http://dx.doi.org/10.22410/issn.2176-3070.v10i3a2018.1907

http://www.univates.br/revistas

\title{
ESTATUTO DO IDOSO E SUA APLICABILIDADE: O CUIDADO DE ENFERMAGEM EM UMA ESTRATÉGIA SAÚDE DA FAMÍLIA
}

\author{
Sabrina Aparecida Likes ${ }^{1}$, Paula Michele Lohmann², Luís Felipe Pissaia ${ }^{3}$, \\ Arlete Eli Kunz da Costa ${ }^{4}$
}

Resumo: O número de idosos vem crescendo consideravelmente nas últimas décadas, estudos científicos demonstram que em 2050 teremos mais idosos, que taxas de nascimento de crianças. $\mathrm{O}$ objetivo do estudo foi conhecer a aplicabilidade e o conhecimento dos enfermeiros sobre o Estatuto do Idoso em unidades de Estratégia Saúde da Família de um município do interior do Vale do Taquari/RS. Trata-se de um estudo de natureza qualitativa, do tipo exploratório e descritivo. Os participantes do estudo foram dez enfermeiros que atuam na unidade. A coleta de dados ocorreu por meio da realização de entrevistas. Observou-se que os enfermeiros se preocupam em orientar e trabalhar com a rede de apoio, sobre o Estatuto do Idoso na sua área de trabalho. Desenvolvendo ações que buscam formas de qualificar o conhecimento de ambas as partes e resolutividade do problema surgido, assim preconizam uma qualidade de vida para o idoso, no decorrer de seu envelhecimento.

Palavras-chave: Idoso; Saúde do Idoso; Estratégia Saúde da Família; Enfermagem.

\section{INTRODUÇÃO}

De acordo com a Organização Mundial da Saúde (OMS), o Brasil vem crescendo nas últimas décadas em relação à população de idosos. Para que se considere um indivíduo idoso em países desenvolvidos o indivíduo deve ter o limite de 65 anos ou mais de idade, já para países em desenvolvimento, considerasse 60 anos ou mais de idade (OMS, 2002).

1 Acadêmica de Enfermagem. Universidade do Vale do Taquari - Univates.

2 Enfermeira. Doutoranda em Ambiente e Desenvolvimento. Universidade do Vale do Taquari - Univates.

3 Enfermeiro. Mestrando em Ensino. Universidade do Vale do Taquari - Univates.

4 Enfermeira. Doutora em Ambiente e Desenvolvimento. Universidade do Vale do Taquari Univates. 
Estima-se que, o número de idosos e a crescente expectativa de vida do idoso no decorrer dos anos, vem do envelhecimento bem-sucedido, que é nada mais que um conjunto de valores culturais de cada indivíduo visto a importância de cada um na sociedade. Os ocidentais tendem a tornar importante a inexistência de doenças, entretanto as sociedades orientais colocam em primeiro lugar o conhecimento, a religião, deixando os problemas de saúde em último lugar (FERREIRA, 2013).

Neste sentido, devemos levar em conta a história de vida e o passado do idoso, desde criança, até processo de envelhecimento da pessoa, não levando em consideração somente fatores negativos de perdas, mas sim o envelhecer com qualidade de vida. O envelhecer com qualidade de vida possibilita uma amplitude maior sobre o conhecimento do envelhecer, como funciona a realidade de seu histórico vivido e respeitado seu passado e presente (SOUZA; HORTA, 2012).

Torna-se visível que o idoso, ao longo dos anos, percorre uma jornada na busca de seus direitos perante a sociedade, foram anos de lutas para que entrasse em vigor o Estatuto do Idoso, este fato ocorreu em $1^{\circ}$ de janeiro de 2004, através da Lei n. 10.741, de $1^{\circ}$ de outubro de 2003. A aprovação desta lei trouxe benefícios que garantem uma melhor qualidade de vida aos idosos. $\mathrm{O}$ mesmo foi criado estabelecendo direitos como, liberdade de escolha, respeito, saúde, de forma onde aconteça integralidade, buscando observar estado físico, mental, espiritual, ou seja, olhando indivíduo no seu todo (BRASIL, 2003).

$\mathrm{Na}$ área da saúde. a medida que ocorrem os atendimentos aos idosos, considera-se que a compreensão dos profissionais de enfermagem, sejam voltados ao entendimento de um envelhecer com alterações no organismo em geral da pessoa idosa. Demostrando assim, competências técnicas e profissionais para lidar com a diversidade de situações apresentadas, por essa população, levando em consideração os direitos e deveres da pessoa idosa, bem como sua experiência de vida acumulada (VALCARENGHI et al., 2012).

Já para Oliveira et al (2011) a Estratégia Saúde da Família (ESF) possibilita ao idoso uma visão ampliada do seu estado de saúde e direcionada ao âmbito da família, pois estabelece vínculo de cuidado de maior grau da realidade vivida na população idosa na comunidade onde reside. $\mathrm{O}$ art. 15 do Estatuto do Idoso assegura a atenção integral da saúde, por intermédio do Sistema Único de Saúde (SUS), garantindo acesso universal, em conjunto articulado e contínuo das ações e serviços.

De acordo com Silvestre e Costa Neto (2003), os profissionais que trabalham na ESF, deve atender um ser humano, vivendo em sua totalidade, em seu esplendor, equilibrado em si mesmo e em todas as suas relações e estado de saúde, seja mental, física e espiritual, ou seja, olhando o indivíduo como um todo. O trabalhador da área de saúde deve vislumbrar na população onde atua o contexto da saúde do idoso, propiciando igualdade e dignidade na melhoria 
de sua qualidade de vida, promovendo respeito, possibilitando perceber, antes de acontecer os agravos.

O enfermeiro ao cuidar do idoso deve orientar sobre os direitos do mesmo, relacionando às legislações, os benefícios concedidos aos mesmos, tais como, acesso ao serviço de saúde, trabalho, esporte, lazer, moradia, com vistas ao processo de envelhecimento saudável e produtivo. O enfermeiro cria vínculo com o idoso, fazendo com que ele se enxergue como útil e visível para o mundo, que o cerca, qualificando sua autoestima e autonomia, diante da sociedade, possibilitando ao idoso uma busca ativa de se conhecer e trabalhar convívio e saúde psicológica (APARECIDA; KUSUMOTA, 2007).

A falta de informação dos usuários priva-os de conhecer seus direitos e deveres de saúde. Observa-se que, quanto maior o nível de informação do usuário sobre os objetivos, e funcionamento da ESF, maior o grau de satisfação. O desempenho em relação ao serviço oferecido e suas formas de trabalho, junto à comunidade, possibilitam uma maior adesão aos processos de promoção e prevenção. O nível de informação está condicionado, entre outros aspectos, pela eficácia das estratégias de comunicação e informação em saúde utilizada, este conhecimento proporcionará ao serviço de saúde um trabalho conjunto de interesses, onde visa uma melhor qualidade de vida (APARECIDA et al., 2016).

Sendo assim, este estudo possui como objetivo, conhecer a aplicabilidade e o conhecimento dos enfermeiros sobre o Estatuto do Idoso em ESF de um município do interior do Vale do Taquari/RS.

\section{METODOLOGIA}

Trata-se de um estudo de cunho qualitativo, do tipo exploratório e descritivo. A pesquisa foi desenvolvida com a participação de dez enfermeiros atuantes em ESF do Vale do Taquari/RS.

Inicialmente o pesquisador realizou contato com a Secretaria Municipal de Saúde, onde na ocasião explicaram-se os objetivos do projeto, bem como, os critérios éticos que norteiam o processo. Após a liberação para execução do estudo por meio de carta de anuência, realizou-se contato com os enfermeiros para apresentação do projeto.

Para seleção dos participantes, aplicaram-se critérios de inclusão, sendo enfermeiros que atuam na área de ESF; que atuam no mínimo há seis meses; Profissional com formação superior a seis meses; critérios de exclusão: Profissional que se encontra em férias, licença maternidade ou folga; profissional que atua a menos de seis meses; Profissional com formação inferior a seis meses.

A coleta de dados foi realizada em entrevista individual, utilizandose de um questionário aberto, semiestruturado, que guiou os diálogos entre pesquisador e participante. As entrevistas tiveram duração média de trinta minutos e tiveram seus áudios gravados. 
Após a finalização das entrevistas, os áudios foram transcritos e analisados conforme propõe a Análise de Conteúdo de Bardin (BARDIN, 2011). Visando reduzir a exposição dos participantes, utilizaram-se codinomes para nominar as menções durante o estudo, utiliza-se a letra "E", seguida de números ordinais aleatórios. O projeto de pesquisa seguiu os preceitos da Resolução $466 / 12$, a qual define os critérios éticos para pesquisas desenvolvidas com seres humanos.

\section{RESULTADOS E DISCUSSÃO}

Quanto a caracterização dos participantes do estudo, quatro possuem especialização, sendo que um deles realizou na área da saúde do idoso. A idade oscilou entre 30 a 49 anos, o tempo de formação variou de 8 a 17 anos de formado. Sobre a atuação em serviço público temos: dois entrevistados com tempo de trabalho entre 3 anos e 17 anos, demais referiram nove meses de atuação.

Após a análise das informações, realizou-se a categorização dos resultados. Sendo a primeira, Capacitação profissional para atenção ao idoso, relacionado ao estatuto do idoso e demandas da unidade para os mesmos, a segunda, Dificuldades enfrentadas na aplicabilidade do estatuto e de que forma abordar o assunto com o idoso e a última, Concepção sobre a consulta de enfermagem ao idoso e grupos de convivência.

\section{Capacitação profissional para atenção ao idoso relacionado ao estatuto do idoso e demandas de cuidados aos mesmos, trazidas para unidade}

A maioria dos informantes da pesquisa relatou não terem recebido nenhuma capacitação sobre o estatuto do idoso, sendo estes sete profissionais e três mencionaram ter recebido. Estes profissionais visam crescimento do idoso em seu município, e trabalham no benefício da capacitação para benefícios na qualidade de vida ao idoso em conjunto com estatuto. Conforme falas de E1 que segue: "Nunca fui capacitada especificamente sobre a lei, nem participei de algum curso sobre saúde do idoso. Porém o estatuto é um documento de fácil acesso".

Para que o idoso desenvolva a autonomia e qualidade de vida neste momento, é de grande importância que os profissionais, que cuidam de sua saúde estejam capacitados, para que juntos trabalhem para o envelhecer saudável (MARTINS et al., 2007). Em relação à capacitação, estudos mencionam que as organizações trabalhistas devem promover capacitações voltadas para o problema da população, na prática da realidade das demandas, acredita-se que os profissionais estarão mais qualificados, motivados e interessados a trabalhar (BOMFIM, 2010).

Desta forma é de extrema importância para as empresas realizem capacitações profissionais, assim beneficiará não somente o profissional como também as organizações, pois com mais conhecimento e motivação este estará 
apto a ajudar em situações, que exigem decisões para bom funcionamento do futuro de ambos (FERREIRA, 2009). Conforme as falas de E4, E10 e E6, respectivamente: "Não há capacitação específica, dirigida ao programa de saúde do idoso junto à SESA, há estímulo para programação, atividades de promoção e prevenção a essa população conforme abordagem e avaliação de cada equipe"; "Sim, na secretaria de Saúde e cursos pelo UNASUS", "Eventualmente capacitações regionais".

A necessidade de capacitação se explica na questão onde, a capacitação busca um preparo para recursos humanos, onde beneficia o conhecimento de ações, como prevenção, proteção e cuidado na capacidade funcional e riscos na saúde em geral da pessoa idosa (RODRIGUES et al., 2007). Portanto considerase que a educação continuada é de extrema importância para profissional depois da formação, pois oferece oportunidades de crescimento para o mesmo de forma que contribua no trabalho exercido (FERREIRA, 2009).

Para os entrevistados em relação às principais demandas que surgem no atendimento na ESF, nos relatos emergiram: questões de vulnerabilidade social, situações de saúde, violência e abandono, como principais. Conforme se observa no relato abaixo:

"Na ESF, que atuo tem uma questão importante de vulnerabilidade social, atendemos muitas situações em que "vive um idoso sozinho" e este precisaria de um responsável para auxiliar nas atividades diárias e na administração de medicamentos, por exemplo. Acho que esta seria a principal situação, que ocorre aqui. Quando estas questões acontecem, geralmente realizamos atendimentos em conjunto com o serviço social. Todas as situações voltadas para o idoso que ocorre privação de direito, são encaminhadas ao CREAS" E1

Observou-se que a população idosa vem crescendo nos últimos anos consideravelmente, portando deve se ter um destaque na atenção social do idoso, levando em conta programas sociais que visem uma melhor idade, com qualidade de vida na sua esfera. Portanto para que o idoso não sofra na sociedade uma vulnerabilidade, estas atividades e ações em conjunto com programas voltados para idoso, devem ser levadas em consideração (ALVES et al., 2010).

O mesmo autor ressalta em seu estudo que deve-se construir uma criação de vínculo entre a equipe, idoso e família, assim junto com trabalho multiprofissional na busca de solucionar as demandas surgidas nas ESF (ALVEZ; BARRETO; SOARES, 2010). Conforme as falas:

"Nós trabalhamos sempre de forma a atender as necessidades do idoso, priorizamos o atendimento deste, realizamos consultas e visitas domiciliares para os idosos. Com maior necessidade sempre usamos o estatuto do idoso" E2 
Tenho muitos pacientes idosos alguns com negligência por parte da família, casos já acompanhado a este paciente se baseia no estatuto do idoso" E6

"Maus tratos ao idoso, vulnerabilidade social, doenças crônicas, quedas, doença mental. O estatuto é aplicado pelo órgão competente do município é encaminhado pela unidade de saúde" E7

Os indicadores demonstram que a violência contra idoso nos serviços de referência, vem trazendo preocupações constantes com as características desta população vitimada. Percebendo que os maus-tratos vêm de familiares e cuidadores, que deveriam dispersar ao idoso um envelhecimento saudável em sua saúde em geral (MINISTÉRIO DA SAÚDE, 2008). Segundo a pesquisa realizada em relação aos idosos e idosas (acima de 60 anos) vítimas de violências atendidas nos serviços de referência, $65 \%$ eram do sexo feminino. A violência moral ou psicológica, que fere a honra ou a intimidade, foi a mais relatada por essa população $(55 \%)$, seguida da física $(27 \%)$, do abandono $(22 \%)$ e, por último, do dano financeiro ou patrimonial (21\%). A violência sexual apareceu em $4 \%$ dessas vítimas atendidas nos serviços de referência de violências. $86 \%$ dessas violências aconteceram na residência e $4 \%$ em vias públicas; $39 \%$ foram atos de repetição (MINISTÉRIO DA SAÚDE, 2008).

Em estudo realizado por Yan, Chan e Tiwari (2014) sobre fatores de risco e de abuso contra o idoso constataram que o mesmo é prevalente em todo o mundo e que estudos prospectivos "sugerem que pessoas mais velhas sujeitadas ao abuso e negligência têm um risco de mortalidade maior do que aqueles que não são vítimas". Silva et al (2016) relatam que:

Nos Estados Unidos, 5 a 10\% de pessoas com 65 anos ou mais de idade foram abusadas por alguém de quem dependem para o cuidado ou proteção. No Canadá, as taxas de prevalência são de $7 \%$ para a violência emocional, $1 \%$ para as questões financeiras bem como abuso físico ou sexual, enquanto que, no Reino Unido, são de $5,4 \%$ para a violência emocional ou verbal, 1,5\% para física e 1,5\% para abuso financeiro. Segundo os autores, é esperado um aumento no número de pessoas idosas vítimas de abuso, dado que muitos países estão atravessando um rápido envelhecimento da população. Isso é particularmente agudo na Ásia cuja população passa por um ritmo de envelhecimento sem precedentes. Em 2012, 11\% dos asiáticos possuíam 60 anos ou mais, um número que deverá subir para $24 \%$ até 2050 . Eles apontam ainda que o maior aumento no envelhecimento da população deverá ocorrer nos próximos 75 anos, chegando a $27 \%$ em 2050, o que, consequentemente, poderá contribuir para o aumento da violência.

A violência ao idoso depende muito de sua renda mensal, ou seja, quanto menor seu valor, mais aumentou o índice de maus tratos, em sua 
residência, pois aquele idoso que adquirir maior estabilidade financeira, na sua velhice, conseguir ter estabilidade, melhor condição de saúde e âmbito familiar. Assim demostrando que financeiramente estes indivíduos tendem ter padrões diferenciados na fase do envelhecer com qualidade de vida (DUQUE et al., 2012).

Torna-se importante que na saúde do idoso, haja uma preocupação com a ocorrência de maus-tratos, especialmente a negligência e o abandono do idoso em sua residência. Destaca também a importância de desenvolver um plano de ação para todos os tipos de violência contra o idoso, em um conjunto com seus familiares e cuidadores deste idoso, promovendo uma qualidade de vida ao idoso (PINTO, 2013; BRASIL, 2003).

\section{Dificuldades enfrentadas na aplicabilidade do estatuto e de que forma abordar $o$ assunto com $o$ idoso}

Na questão de dificuldades enfrentadas na aplicabilidade do Estatuto do Idoso, aos profissionais entrevistados, relataram que conseguem desenvolver um bom trabalho com idoso, em busca de seus direitos. Porém, quando o caso deve ser encaminhado a outra competência e órgão responsável, com trabalho junto ao idoso, que deveriam buscar soluções para casos mais complicados. Dos dez enfermeiros entrevistados, nove, mencionam dificuldade nesse processo. Como mostra logo abaixo:

"Orientamos o idoso em todas as questões e muitas vezes chamamos familiares para devidas orientações normalmente a maior dificuldade são idosos que residem sozinhos e familiares não os auxiliam. Nestes casos encaminhamos para o CREAS que também não consegue auxiliar a todos pela demanda"E2

A forma pela qual se preconiza as questões voltadas para maus-tratos domésticos, sofrido por idosos, em suas residências, devem ser atendidas em conjunto com uma equipe multiprofissional. Sendo que esta busque o apoio, como o Núcleo de Apoio à Saúde da Família (NASF) e também por meio do Centro de Referência de Assistência Social (CRAS) e entidades de defesa aos direitos do idoso (SILVA et al., 2016). Estes órgãos competentes buscam resolutividade e agilidade em beneficio ao idoso, conforme os relatos:

"Eu me sinto bem preparada para a realidade, uma boa orientação, questões burocráticas e com rede" E8

"A orientação ao idoso quanto aos seus direitos são realizadas, mas não tão comum abordar especificamente esta questão. A orientação de que ele tem preferência, por exemplo, já é muito clara aqui na unidade. Assim como, com relação à assistência em saúde, precisa de um olhar especial 
dos profissionais, pois geralmente apresentam fatores de risco associados ou morbidades. Quando surgem dificuldades, contatamos o serviço social, para auxiliar nas orientações ou avaliar necessidades de encaminhamentos para outros serviços da rede, onde não se retorna o caso" E1

Em seu estudo Andrade et al (2016) refere que o idoso consegue ser encaminhado às redes de atenção à saúde, mas este processo é falho e demorado, contudo este enfrenta dificuldades ao encontrar seus direitos, onde muitas vezes este retorno não acontece para esta população e para rede de atenção básica, demonstrando que não existe uma organização adequada nas demandas dos casos e não conseguem dar continuidade ao trabalho iniciado. $\mathrm{O}$ mesmo autor salienta um cuidado na saúde do idoso, um vínculo com relações entre as redes, proporcionando uma devolução das informações, para um trabalho de desenvolvimento do acompanhamento da situação na comunidade, onde reside, objetivando um trabalho com atenção integral ao idoso. Portanto o repasse de informação ao profissional de saúde da rede pública direciona para um trabalho que visa ao todo, na questão saúde dessa população, auxiliando em seus enfrentamentos e problemas surgidos (ANDRADE et al, 2016).

Quanto aos momentos para ser falado sobre o estatuto do idoso, todos os entrevistados relatam já ter abordado, em várias situações. Concretizando que todos os enfermeiros entrevistados, relacionam o Estatuto do Idoso, como primordial na busca de melhorias na saúde dessa população. Os enfermeiros se preocupam com o assunto proposto e conseguem, de alguma forma, aplicar com os idosos, na sua ESF. Ao analisar as respostas a seguir, podemos observar que estão sendo desenvolvida com qualidade a busca da informação sobre os direitos do idoso por parte dos enfermeiros, conforme as falas:

"Os direitos do idoso devem ser levados em conta sempre que houver necessidade. Além disso, atividades de educação em saúde, informando a eles os seus direitos, também são importantes" E1

\section{"Sempre que conversamos e atendemos um idoso" E2}

Os direitos do idoso devem ser respeitados, cumpridos e informados, de forma que se faça valer seus direitos primários, que são eles: moradia, alimentação, esporte elazer. Essa população será acompanhada por profissionais capacitados para atender as realidades vividas do envelhecimento no contexto da sociedade onde residem, pois é em uma visita domiciliar, que se encontra a realidade vivida pelo idoso (FERREIRA, 2013). Conforme a fala abaixo:

"O estatuto prevê serviços especiais de prevenção e atendimento às vítimas de negligência, maus tratos e nosso, rede está estruturada para atender situações de violência com auxílio dos CRAS e CREAS, por meio de apoio jurídico pelo MP de Lajeado" E3 
Destaca-se, que a violência na saúde do idoso, deve ser detectada no seu atendimento, ou seja, na consulta de enfermagem, onde é possível encontrar formas de ações e programas voltados para o enfoque de desleixo ao idoso. A saúde pública pode estar qualificando e garantindo, de maneira eficaz, o cuidado na esfera familiar desta população (CASTRO et al., 2013). O mesmo autor explica que quando surge uma demanda de agravos na saúde do idoso na Atenção Básica, é avaliado risco que este idoso vem sofrendo em sua localidade, portanto se começa um trabalho burocrático com CREAS para que aconteça uma resolutividade do problema que surgiu na equipe (SILVA et al., 2016).

O benefício de uma visita domiciliar realizada com eficácia no atendimento transmite ao idoso, família e cuidador um apoio de cuidados, na sua realidade vivida e suas dificuldades enfrentadas, no decorrer dos seus dias e junto orientando as formas de cuidados. Podendo este profissional ficar atento às questões de negligência com idoso, assim pode estar usando o estatuto como forma de garantir seus direitos e conhecê-los da mesma forma (MINISTÉRIO DA SAÚDE, 2006). Conforme as falas de E6, E5 e E8, respectivamente: "Sempre em atendimento, consulta de Enfermagem e nos grupos de idoso", "Consulta de Enfermagem, visita domiciliar e visita das ACS" e "Devemos aproveitar toda oportunidade que estamos com eles".

Portanto é de extrema importância o Estatuto do Idoso, concretizando assim um envelhecer digno e saudável ao mesmo, onde seus direitos fortalecem uma saúde integra. Nesse sentido, devem ser trabalhadas mais ações conjuntas com família, idoso e equipe de saúde, criando um vínculo para fortalecer o conhecimento de ambos e atuar em conjunto. Para que o estatuto do idoso seja concretizado e se faça valer seus direitos deve se realizar um trabalho em conjunto com os enfermeiros das ESF (SILVA et al., 2016; MINISTÉRIO DA SAÚDE, 2006).

\section{Concepção sobre a consulta de enfermagem ao idoso e grupos de convivência}

No decorrer das entrevistas, percebe-se que os enfermeiros entrevistados se preocupam com o idoso em suas consultas e que estes demostram um olhar mais criterioso na atenção dos mesmos, desenvolvendo diagnóstico, não só voltado para patologias e sim voltada também para negligências, assim se preocupam em investigar, mostrando-se preocupados com as situações e contatando de forma investigativa na demanda trazida, por esta população, com rede de apoio, e promovendo ações educativas para interagir com idoso e conhecimento de seus direitos. Como será mostrado na fala abaixo:

"Já me deparei com hematomas e escoriações no atendimento a idoso e procurei conversar diretamente com idoso oportunizando a ele falasse sobre o assunto e salientando que a consulta é sigilosa. Cada caso é um caso. As vezes o idoso vive uma questão que não que levar adiante uma situação 
de violência e ai vamos conversando e tentando auxiliá-lo, sem que ele também perca a confiança em nós. Contatamos com as agentes de saúde que procuram avaliar na casa do paciente o que acontece e, as vezes, até na sua vizinhança, com muito cuidado para não haver exposições." E1

Isto se evidencia na explicação que o enfermeiro deve saber ouvir uma linguagem corporal na consulta de enfermagem com idoso, pois este diferencial pode destacar um agravo na saúde desta população, ou seja, se na linguagem corporal, pode haver mais do que o idoso tem a dizer para o profissional, porém este deve transmitir segurança e sigilo ao paciente. No atendimento ao idoso é preciso levar em conta seu estado físico, psicológico, comportamental, patologias, saber mais sobre seu convívio na sociedade, como está sendo seu dia-dia com os familiares (FERREIRA, 2013). Tal explicação é verificada na fala de E8: "Fazendo uma boa conversa, conquistando confiança do paciente e mostrando a ele que quero ajudar, se caso ele não me conte a situação de maus tratos, após consulta, eu entro em contato, sem que haja investigação da situação".

$\mathrm{O}$ atendimento ao idoso em suas consultas de rotina na ESF demonstra que com atenção ampla do enfermeiro, pode identificar uma violência e danos que este idoso vem sofrendo. Assim este profissional tem um papel importante a ser trabalhado junto com idoso, família e com os órgãos competentes no sentido de preservar a integridade física e psicológica do desta vítima de violência, traçando em conjunto formas de resolutividade dessa demanda observada na consulta de enfermagem (OLIVEIRA, 2015).

$\mathrm{Na}$ consulta de enfermagem se agrega melhoria na vida do idoso, de modo que identificando seus problemas individuais e traçando planejamentos podemos solucionar a situação trazida (ANDRADE et al., 2012). O mesmo autor prioriza a consulta de enfermagem nas ESF como um elo de equilíbrio é decisivo aos idosos. Não se pode conceber uma atenção básica, como o caso da ESF sem uma consulta de enfermagem qualitativa. Essa deve ser ponto de harmonia nas dificuldades trazidas pelo público alvo, buscando auxilio junto às redes de apoio (ANDRADE et al., 2012).

A consulta de enfermagem, ao idoso na ESF, como o apoio das políticas de atenção à saúde dessa população, deve ser revestida na investigação do histórico desse idoso, como ele vem sendo tratado no familiar, seu estado mental, seu estado físico e com estas informações, o enfermeiro deve elaborar um plano de prudência e zelo, proporcionando um bem-estar no decorrer da sua vida (SILVA et al., 2016).

Quando deparado com surgimento de grupos para idoso, na ESF, onde enfermeiro atua, estes enfatizam que são realizados poucos encontramos específicos, visto que somente três entrevistados realizam, mas colocam que existem outros grupos, que na maioria das vezes os que mais frequentam são idosos. Conforme segue os relatos abaixo: 
"Na unidade fazemos de tudo um pouco, atualmente conseguimos realizar ações de promoção, prevenção e recuperação de saúde. Os problemas que surgem vamos tentando resolver conforme tem necessidade. A equipe e principalmente as agentes de saúde levam para reuniões de equipe "situações-problema" e vamos resolver conforme nos cabe. Somos uma equipe que costuma dar muita importância para estas questões. Com relação aos grupos de promoção em saúde, não temos um grupo de idoso, mas temos alguns grupos onde esse público é convidado e participa, entre eles grupo de educação em saúde e o grupo de autoestima, além disso, é de costume fazermos atividades alusivas, por exemplo, a saúde do homem, da mulher, de combate a AIDS, de prevenção ao suicídio e, os idosos sempre são incluídos nessas atividades" E1

"Saúde do idoso: Sempre que necessário abordo o assunto e converso. Temos 2 grupos na comunidade onde são feitas rodas de conversa e abordados os mais diversos assuntos" E4

Os grupos são definidos como um conjunto de interesses dos quais participam, é onde se discute sobre temas gerais a escolha dos mesmos interessados, onde tratam sobre dificuldades trazidas no seu dia-dia. Este trabalho com grupos é de extrema importância para criar um elo de apoio e confiança entre o enfermeiro e idoso, visando um ambiente de apoio, orientação, troca de conhecimentos, enfatizando um trabalho na saúde do idoso (MINISTÉRIO DA SAÚDE , 2006).

\section{CONSIDERAÇÕES FINAIS}

O presente estudo demonstrou que os enfermeiros da ESF, onde foi realizada a coleta de dados, estão em busca de benefícios e aperfeiçoamento em relação à saúde do idoso, seja através de capacitações, ou encontros que abordem os direitos dos mesmos. Porém foi visto que no serviço onde esses enfermeiros atuam, não foi realizado nenhuma capacitação até momento.

Desta forma é importante sensibilizar os gestores sobre a importância de educação continuada que aborde este publico alvo, a partir daí sendo possível de se tomar decisões e encaminhamentos de forma que possibilite uma resolutividade na saúde em geral desse idoso. Neste estudo observa-se um ponto relevante e diferencial do enfermeiro, junto consulta de enfermagem ao idoso, pois neste momento procuram visualizar de forma holística e com interpretação, além do que o idoso refere demonstrando grau de aperfeiçoamento desses profissionais na saúde pública.

Diante de este olhar, o enfermeiro no seu trabalho na saúde publica, pode estar ajudando na saúde do idoso, na questão não somente de patologias, mas sim, de negligências e maus tratos, onde muitas vezes não são revelados na consulta de enfermagem. Assim, mais uma vez entra os seus direitos, previstos 
por lei, sendo que este profissional frente a esta situação inicia trabalho para amenizar o sofrimento do idoso.

Concluímos que é evidente a necessidade de capacitação e abordagem desse assunto na rede de atenção à saúde, bem como que as instituições de ensino viabilizem essas formações. Portanto o trabalho que os enfermeiros desenvolvem na saúde do idoso, junto com apoio do Estatuto do Idoso é de estrema importância para uma qualidade na vida dessa população,

Sendo que a população idosa recebe como benefícios, o conhecimento de seus direitos e também apoio de suas leis, diante de suas dificuldades surgidas no caminhar de seu envelhecimento. Os enfermeiros entrevistados demostram se preocupar em aplicar e passar conhecimento sobre o estatuto para o idoso, seja através de uma consulta de enfermagem, visita domiciliar ou demandas trazidas para estratégia de saúde.

\section{REFERÊNCIAS}

ALVEZ, J.C; BARRETO, P. C; SOARES, M. L. Vulnerabilidade Social da População Idosa e a Necessidade de Políticas de Proteção como Mecanismo de Inclusão Social. Qualit@s Revista Eletrônica,v. 9, n. 1, 2010.

ANDRADE, A. M. et al. Promovendo a saúde na terceira idade: a consulta de enfermagem em análise. CONVIBRA. 2012.

ANDRADE, L. M. O. et al. Percurso do idoso em redes de atenção à saúde: um elo a ser construído. Physis Revista de Saúde Coletiva, Rio de Janeiro, v. 26, n. 1, p. 45-62, 2016.

APARECIDA, C. S. et al. Atuação de Enfermeiro na Estratégia de Saúde da Família em um Município de Minas Gerais. Saúde - Santa Maria, v. 42, n.1, p. 49-58, jan./jun. 2016.

APARECIDA, R. P. R.; KUSUMOTA, L. Política nacional de atenção ao idoso e a contribuição da enfermagem. Texto Contexto Enferm, Florianópolis, n. 3, p. 536-45, 2007.

BARDIN L. Análise de conteúdo. São Paulo: Edições 70; 2011.

BOMFIM, C. B. Capacitação Profissional e sua articulação com prática de Enfermeiros. Salvador, 2010.

BRASIL Parecer n. 1301 de 2003. Estatuto do idoso. Projeto de Lei da Camarada n.57. Brasília, DF: Senado Federal, Comissão Diretoria, 2003.

CASTRO, A. P. et al. Violência na velhice: abordagens em periódicos nacionais indexados. Ciênc. saúde coletiva, v. 18, n. 5, Rio de Janeiro, Mai, 2013. 
DUQUE, A. M. et al. Violência contra idosos no ambiente doméstico: prevalência e fatores associados. Ciência \& Saúde Coletiva, v. 17, n. 8, p. 2199-2208, 2012.

FERREIRA, D. M. Negligencia e maus tratos contra idoso: Como minimizar esses problemas. UBERABA-MG. 2013.

FERREIRA, J. C. O. A.; KURCGANT, P. Capacitação profissional do enfermeiro de um complexo hospitalar de ensino na visão de seus gestores. Acta paul. enferm. [online]. v. 22, n.1, pp.31-36, 2009.

MARTINS, J. J. et al. Políticas públicas de atenção à saúde do idoso: reflexão acerca da capacitação dos profissionais da saúde para o cuidado com o idoso. Revista Brasileira de Geriatria e Gerontologia, v. 10, n. 3, pp. 371-382, 2007.

MINISTÉRIO DA SAÚDE. Envelhecimento e saúde da pessoa idosa. n. ${ }^{\circ} 19$ Brasília DF 2006.

MINISTÉRIO DA SAÚDE. Painel de indicadores SUS. 2008.

OLIVEIRA, J. M. Atuação do enfermeiro perante a violência doméstica sofrida pelo idoso. Rev interdiscipl. envelhec., Porto Alegre, v. 20, n. 2, p. 365-379, 2015.

OLIVEIRA, T. R. Ações Sistematizadas no atendimento ao idoso pela equipe de Saúde da Familía. Conselheiro Lafaete - MG. 2011.

OMS. Organização Mundial da Saúde. Relatório mundial sobre violência e saúde. Geneva, 2002.

PINTO, R. Idoso Vítimas de violência: Fatores Sociodemográficos e subsídios para futuras intervenções. Estudo e Pesquisa em Psicologia. 2013.

RODRIGUES, J. O docente de enfermagem e sua representação sobre a formação profissional. Esc Anna Nery R Enferm, v. 11, n. 3, p 494 - 9, 2007.

SILVA, C. F. S. et al. Violência Contra Idosos na Família: Motivações, Sentimentos e Necessidades do Agressor. Psicol. cienc. prof. v. 36, n. 3, Brasília July/Sept. 2016.

SILVESTRE, J.; COSTA NETO, M. M. Abordagem do idoso em programas de saúde da família. Cad. Saúde Pública, v. 19, n. 3, Rio de Janeiro, Jun, 2003.

SOUZA, C. M. R.; HORTA, N. C. Enfermagem em Saúde Coletiva e pratica: Rio de Janeiro: Guanabara Koogan. 2012. Livro Grafico. cap 9 pag, 117.

VALCARENGHI, R. V. et al. Produção científica da Enfermagem sobre promoção de saúde, condição crônica e envelhecimento. Rev Bras Enferm. v. 68, n. 4, p. 705-12, 2015. 